This is a preprint of an article whose final and definitive form has been published in the BRITISH JOURNAL OF SOCIOLOGY OF EDUCATION (C [2007] [copyright Taylor \& Francis];

\title{
An exploration of young children's ethnic identities as communities of practice
}

\section{Ian Barron}

\section{(6996 words including abstract and references)}

\begin{abstract}
This study is concerned with experiences of ethnic identity amongst a group of three and four year old children, four - fifths of whom are of Pakistani-heritage and the remainder of white indigenous-heritage. Focused on a nursery school in the United Kingdom, the study explores the relationship between the individual and the social and cultural, initially in the home and then as the children start nursery school. An ethnographic approach is used in order to record the children's daily experiences and relationships as contexts where they reveal, shape and reshape who they are. Children's ethnic identities are explored in relation to boundaries where different communities of practice collide, alongside other aspects such as gender and sexuality and under the influence of factors such as power and religion. What appears to emerge is a sense of ethnic identity as social practice and performance rather than as the result of maturation or of internal cognitive development.
\end{abstract}

Keywords: ethnic identities, communities of practice, ethnography 


\section{Introduction}

This paper seeks to explore the experiences of ethnic identity of children aged three and four and draws upon fieldwork carried out as part of my doctoral studies. There is very little existing literature, in English, that considers the nursery school years, though there are numerous studies of ethnic identity in adolescence (e.g. Phinney, 1990) and a smaller number concerned with the primary years (e.g. Connolly 1998). Work such as that by Rhedding - Jones (2002) and Brooker (2002) has begun to consider ethnic identity but the main concern has been with examining the ways in which different forms of cultural learning lead to particular educational outcomes for children and with how far provision reflects children's ethnicity and culture. In these accounts, ethnic identity tends to be treated in ways that suggest essentialism and Rhedding-Jones (2002, p.94) argues that 'moving towards fluid multiplicities, where people belong to a range of simultaneously operating categories, beyond a binary, remains a challenge'. The present study seeks to engage with the complexities of children's ethnic identities, rather than with discrimination, and to view their every day activities as sites where something may be gleaned about what ethnic identities might mean and how they are lived out and enacted by children as they interact with other children and with adults. As Hall (2003, p.93) notes 'we still have a great deal of work to do to decouple ethnicity, as it functions in the dominant discourse, from its equivalence with ..... racism'. Verkuyten (2005) argues that there has been very little research that has looked at how people give meaning to their ethnic identities in their everyday situations. This is precisely the key concern of the present study as it seeks to engage with the complexities of how ethnic identity is experienced, practised and performed by a particular group of children in the contexts of their homes and nursery school. 


\section{Models of identity}

\section{Identity as Internal and External Processes}

The study of identity has tended to start either from the individual and has been concerned with the internal or has started from the social and explored the external. Constructivist models of development, such as the stage - based theory of Piaget (1954), tend to see children's understanding of aspects of identity as largely cognitive processes. Understandings relating to ethnic identity, are considered to form relatively late because they are seen as requiring understandings about self and other that children are thought incapable of until the later primary school years. Alongside constructivist theories of stage - based identity development, psychoanalytical approaches, such as Freud's (1991) psychosexual theory, view the conflict between the id, ego and superego as the means by which the individual's identity is formed. Gender and sexual identity are seen as fixed and stable and the drive is towards an essentialist and normative notion of what being male and female means and towards an assumed ideal of heterosexuality.

The challenge remains, however, to identify a model of making the self that breaks free of construction purely within the individual. Work such as that by Vygotsky (1978) has been particularly helpful in providing a conceptual framework where development and learning are both internal and external. They are seen as shaped by interaction with more knowledgeable others, in particular social and cultural contexts, making use of 'cultural tools', later internalised as psychological process. More recent critical accounts of identity, including Lacan's (1989), 
however, could be seen to retain many psychoanalytical pre-given notions, including the central significance of internal psychological conflicts. Sondergaard (2002) offers a useful alternative to such notions. She suggests that what is needed is an understanding of the ways in which localised 'discursive repertoires' (Sondergaard, 2002, p.452) construct aspects of identity such as gender, sexuality and ethnicity and of the ways in which these reflect context - specific as well as socio-cultural and historical understandings. In place of a view of identity as internally driven process, she suggests that what is then needed is an understanding of how these aspects of identity become incorporated into individual consciousness through a process of sifting and synthesising.

\section{Identity as Performance}

This begins to open up a theoretical framework that fuses the cognitive with the social in a constant interplay of negotiated and distributed iterative practices spanning the individual and the communities in which s/he lives, a model viewed as useful in this study. Butler's work (1999) on gender identity is also helpful here with its conceptualisation of identity as ' $\ldots$ instituted through acts which are internally discontinuous .... the appearance of substance is precisely that ...a performative accomplishment which the social audience, including the actors themselves,

come to believe and to perform in the mode of belief' (Butler, 1999, p.179). In a similar vein, Barth's claim (1966) is that ethnic identity is performed along a boundary of internal and external markers in relation to ever changing notions of what the players see as significant points of similarity and, more importantly, difference. The shifting boundaries, Barth later argues $(1989,2000)$ reflect a post-modern world where ethnicity is played out in different 'discrepant' 
contexts within 'partial and simultaneous worlds' which are 'not of one piece' (Barth, 1989, p.130) and which involve political dimensions of 'systematic indoctrination whereby authoritative teachings are drummed in and elevated to dogma ... there will be positive encouragement for cognitive assent and agreement .... and sanctions will be brought to bear against its breach' (Barth, 2000, p.27).

The work of Bhabha (1994), brings together Barth's contention that ethnicity is negotiated at boundaries with Butler's notion of performativity (1999). Like Barth (1966), Bhabha argues against the notion of essentialism and conceives of ethnic and cultural identities as mimic performances that come to be repeated and understood as part of an often illusory notion of heritage. In a similar vein, Nayak (2006, p. 416) argues that racial and ethnic identities are 'a fiction only ever given substance to through the illusion of performance, action and utterance, where repetition makes (them) appear as-if-real'. Following Foucault (2002), for Bhabha (1994, 1996) and Nayak (2006) power operates within communities to suggest the value of particular performances in which ethnic and cultural identities are tenuously stitched together.

What emerges from the above is a sense, as Giddens (1991, p.3) argues, that the self involves the reflexive and continuous construction of multiple identities from 'a puzzling diversity of options and possibilities'. Significantly, it is believed, for the present study, Brah argues (1996) that aspects of identity are constructed in an articulation which involves gender, 'class, race, ethnicity and sexuality' (p.67). Equally importantly, Brah (1996) introduces the notion of 'diaspora space', which is important in conceptualising the dynamic nature of ethnicity. Diaspora spaces 
are where 'contemporary forms of transcultural identities are constituted; and where belonging and otherness is appropriated and contested' (p.242).

\section{Diasporic Ethnic Identity in the Nursery: Exploring Communities of Practice}

In seeking to conceptualise further how children come to experience, engage in and perform their ethnic identities, Lave and Wenger's notion of communities of practice (1991) is considered a useful framework. In this model, those with fewer skills and less knowledge and understanding (of ethnic identity in this case) are seen as engaging, initially, in legitimate peripheral participation in the community of the skilled and knowledgeable. Wenger (1998) draws parallels between the processes that are involved in learning skills through legitimate peripheral participation in community practices and those that are involved in shaping identity. Institutions (such as the nursery school, in this case) may provide for legitimate peripheral participation in ethnic and cultural identities or they may seek, advertently or inadvertently, to refuse participation. Ethnicity, for Wenger (1998), is negotiated and marked at the boundary between what one is and what one is not.

These shifting moments of negotiation at the boundary are the connection with what Brah (1996) terms 'diaspora spaces'. Individuals (including the children in the present study) are conceived as enmeshed within communities of practice at micro, meso and macro levels, which provide unity and disunity, which connect and disconnect and where power operates at the same levels to shape ethnic identity. This shaping is a constant dance of positioning with moments of continuity, discontinuity, participation, peripheral participation, marginalisation, disidentification and resistance. The concern of the present study was with studying the interplay and the tension 
which Wenger (1998) identifies as the children come to develop diasporic identities of full, partial or non - participation in the meanings about ethnic identity that are negotiated and renegotiated in their families and the nursery school.

\section{The research}

\section{Context}

The fieldwork was carried out in a nursery school in North - west England, where four-fifths of the intake was of Pakistani-heritage and one-fifth of white indigenous-heritage. The nursery school is located in an area that comprised small terraced houses when the nursery school was built in 1950 but which was redeveloped in the late 1980s. A mosque has opened recently in a building directly behind the school. Thirty-two children were observed over a five month period. The children comprised half the morning and half the afternoon class in each case. The children were selected using two criteria. The first was gender: eight boys and eight girls were studied from each of the morning and afternoon groups. The second was ethnicity: from each session, four were of white indigenous-heritage and twelve of Pakistani-heritage, reflecting the overall present ethnic mix of the nursery school. The inclusion of both sexes was intended to enable some consideration of the interplay of gender and ethnicity in the construction of ethnic identity. 


\section{Research Strategy}

The research paradigm underpinning the present research starts from the premise that social reality pre-exists but depends on and continues after those who currently shape it. At the level of epistemology, the stance is that the evidence that emerges from research can never consist of the final word in term of facts or knowledge. Bearing in mind the lack of previous research into young children's experiences of ethnic identity, an ethnographic approach appeared the only tenable way in which to undertake the study.

Objections could be raised that the ethnographic approach is overly subjective, that it is only the researcher's opinion. Certainly there were moments of unease about what had been missed and about why certain things had or had not been written down but all of this assumes an objective reality that is being contested. As Emerson et al note (2001, p.353): 'field notes are inevitably selective. The ethnographer writes about certain things that seem 'significant', ignoring and hence 'leaving out' other matters'. In order to help deal with these issues, as well as to try to take account of as many points of view as possible, aspects of the fieldwork that seemed significant, and my interpretation, were routinely shared with the staff and their opinions sought. This process destabilises the supposed objectivity of research and raises questions about 'the boundaries that research conjures, and maintains, in order to produce truth, certainty and authenticity .... The possibility of any breach in those boundaries is .. generally treated as a threat to be contained, lest mischief and paradox should be unleashed upon an orderly world' (Maclure, 2003, p.149). Once it is accepted that there can be no privileged place for the omniscient view of the researcher, what emerges is the writer's need to interrogate his/her own subjectivity in a process of auto-ethnography (Goodley et al, 2004) that creates the 'messy text' 
(Marcus, 1994, cited in Plummer, 2001) in '..an intense problematizing of the whole field' (Plummer, 2001, p.398). The auto-ethnography and the concern to engage with rather that create distance from the researched is consistent with the view of identity (both ethnic and researcher) as social practice. Thus the auto-ethnography that emerged sought to represent different points of view and multiple tellings.

It remains true, however, that the auto-ethnography remains my understanding of what they said and my selective representation of it. By using auto-ethnography, the intention was, at least, to avoid establishing an invisible authority for the interpretations. Whilst an attempt was made to represent differing view points in the written account, this is not the same as saying that participants' view points were necessarily accepted and nor that matters were portrayed wholly as they saw them. Whilst there cannot be a claim to have understood the enactment of identities in the same ways as the participants, there was at least an attempt to engage in numerous and contrasting analyses whilst recognising that what was recorded and analysed could only ever be personal, selective and partial. This stance may be seen to take us to the very limits of the comfortable and raises questions about what we can possibly hope to find out in a world of multiple realities. The present study seeks to treat 'mischief and paradox' as phenomena 'to be engaged rather than evaded' (Maclure, 2003, p. 149).

\section{Fieldwork}

The study began with a week in which I visited the children's homes alongside nursery staff in August 2004 before they started nursery school. This was intended to enable me to understand 
something of the children's homes and prior experiences. This was followed, two weeks later, by a week spent in the nursery school in early September when I observed the same children as they settled into the nursery school. Further fieldwork was carried out in November and December when the nursery was celebrating Eid and Christmas.

\section{Ethical Issues}

Issues of consent are never straightforward but all too often they are presented as though they are concerned with little more than signed consent forms. It is true that the head teacher of the school involved was given information about how the data was to be collected and used, discussed the research with staff and gave consent before the study began, but there are always questions about how far the intentions are understood and how far the individuals feel able to withhold consent. It must be acknowledged that the very exploratory nature of the research also meant, as Hammersley and Atkinson note (1995) that, at the outset, ideas about what the research would entail were relatively vague. In this sense, as in many others, consent had to be continually renegotiated as the research took new turns. Similar information about the research was given to the parents of the children and consent was sought to attend the home visits and to observe the children. Given the potential sensitivity of issues surrounding ethnicity and that the study would also be concerned with matters such as religion, class and poverty, it was important, as Fine et al note (2000), to give careful thought to how to explain the purposes and uses of the research and to how to present it once complete. It must be acknowledged, however, that it was difficult to be certain how far the parents really understood what was being asked of them, given both the difficulties of explaining research intentions and the challenges of communication with many of them, whether verbally or in writing, because of the differences in our first languages. 
The age of the children to be studied (three years) posed particular issues in a number of respects. As Gordon et al (2001, p.188) comment: 'ethnographic research with very young children has been sparse, and the lives of children have often been interpreted from adult perspectives.' The challenge was to attempt to engage with children's understandings and experiences as well as those of others in the communities of practice in which they participated. Following James (1999) and Nilsen (2005), it was considered important to seek to use research methods that enabled the views of the children to be heard without intentionally or accidentally 'othering' them in the process. It required a complex model of what it means to listen to children's voices. This involved a decision to study children's play, actions, paintings, drawings and choice of friends as a means of giving them a 'thickness of voice' that was made up of more than their words. This was considered particularly important in terms of addressing the language challenges posed by the age of the children and the status of many of them as speakers of English as an additional language.

As Corsaro and Molinari (2000, p. 183) also recognise 'the ethnographer's acceptance into the world of children is particularly difficult because of obvious differences between adults and children in terms of cognitive and communicative maturity, power and physical size'. Until very recently, as Aubrey et al note (1998), it has been considered by many researchers to be unnecessary to seek young children's consent, generally because of a belief that they are incapable of understanding and of offering a reasoned opinion. Whilst more attention is now being given to issues of children's consent, genuinely informed consent is even more difficult than it is in the case of adults. In the present study, there was a concern to seek the children's 
approval and, if observing individuals at close quarters, their agreement was sought and an explanation given as to what would be written down. This is not, however, to claim that there are any easy answers to questions of children's rights and consent. In the end, the main consideration had to be to feel satisfied that the children were not being exploited.

\section{Presentation and analysis of findings}

\section{Family, home, community and ethnic identity}

The home visits were intended to shed light on the environment of the home as the locus of practices and performances in relation to ethnic (and other) identities. A particular concern was to study possible outward markers of ethnic identity, such as house decoration and furnishing, language and dress. Amongst the families of Pakistani-heritage, three main decorative styles emerged that appeared to correspond with the affluence and degree of religiosity of the families. The more affluent the families seemed, the more they had adopted Western styles of decoration. About a quarter of the homes were in this style, with wooden floors and rooms decorated in pale colours. About half of the homes of families of Pakistani heritage, fell into another recognisable style where there appeared to be more influence from Islam and from non-Western culture. In these homes, there were bench-style sofas with lids and a storage space inside, clocks with Arabic writing, mosque ornaments, framed pictures of Mecca and extracts from the Qu'ran. The final quarter of the homes appeared to be the least affluent and showed the greatest influence from Islam. These homes often had large unframed extracts from the Qu'ran attached directly to 
the walls. One such home suggests something of the complex cultural spaces in which many families live:

There is a radio receiver ... with prayers .. from the mosque ..... A large clock is surrounded by ... unframed extracts from the Qu'ran above the fire place. The clock itself is decorated with Arabic writing but then plays 'There's no place like home'.

With two exceptions, the families of white - indigenous heritage appeared to be living in challenging financial and social circumstances. With the same exceptions, they lived close to the nursery and in local authority housing. The home of a family from the next town was the most striking exception with new furniture, eight bibles on the book cases, crosses on the doors and a t-shirt with the message 'Jesus Loves Me', hanging on a radiator.

Another element that appeared important to note during the visits was the way in which the children and adults were dressed. In the homes of the families of white indigenous heritage, all of the mothers wore casual clothes such as jeans and t-shirts. In almost all the homes of families of Pakistani - heritage, the mothers were dressed in traditional salwar kameez (the kameez is a long tunic worn over the salwar which are loose fitting, pyjama - like trousers). However, in the least affluent homes, the mothers often spoke little English and whilst none of them wore the jilbab or burkha (variations on a loose full length gown covering the face, head and body), these mothers were the most likely to be most covered. The more affluent mothers appeared to have clothes in richer fabrics and spoke better English. A very small number wore trousers and long sleeved tops, with Western scarves acting as hijabs. The children of white indigenous origin 
wore unremarkable Western clothes. The clothes worn by boys of Pakistani - heritage were usually Western in style except in the poorer homes where some dressed in salwar kameez and sometimes wore jewellery. In many of the homes, the girls were traditionally dressed in salwar kameez and often wore bangles.

The visits led me to question my ability to view the homes other than from a white, British, middle class, male, educated perspective. My feelings of experiencing the 'exotic' in the homes of some of the families of Pakistani-heritage troubled me, as did my struggle to remember to note down what was not 'other'. These feelings made me question the authenticity of much of what I was recording. Thus, as points of significance began to suggest themselves, I found that I was not comfortable in most of the homes, exploring social, cultural and religious worlds that I did not completely understand. It was not simply a case of being unfamiliar with the homes of people of Pakistani - heritage: the poverty experienced by many of the white families was just as unfamiliar and made me feel equally uncomfortable. As Deegan (2001, p. 21) notes, this raises questions such as 'can a stranger ever understand... an 'alien' culture? .... How important are differences between a sociologist and a subject if they vary by age, race, class, gender?'

\section{The Relevance of Socioeconomic Circumstances and Religiosity}

Social class, ethnic origin and degree of affluence thus emerged as significant factors in understanding the influences at work in shaping identities. In some homes, religion was also significant. Whilst studies of social class have traditionally emphasised occupation and income as markers of class divisions, social class is a strongly contested notion. Recent work such as 
that by Archer and Francis (2006) has sought to explore the relationship between class and race in studying the achievement of British Chinese children and has examined how racialised cultural, economic and social capital influence the reproduction of class identities. Vincent and Ball (2006) suggest that family lifestyle, values, political preferences, locality and education may be more helpful than occupation in understanding divisions between and within classes. Reay (2005) argues that what is needed is greater understanding of the connections between the internal affective worlds of individuals and external social structures, processes and markers. Following Sayer (2005), Vincent and Ball (2006) argue for the significance of feelings such as guilt, shame, resentment and defensiveness in setting the boundaries between class positions and Reay (2005, p.913) argues that there are other emotions at work such as 'envy, deference, contempt, arrogance, pride, rage, satisfaction, embarrassment and pity'. These feelings also appear important in understanding the relationship between ethnicity, class and religion.

In the present study, there were indications of Butler's notion (1999) of identity as performative, based on outward signs and 'written on the body' (and the homes) through clothes, hair styles, jewellery and other forms of decoration. The strongest signs of religion as a marker of ethnic identity were in the least affluent homes of families of Pakistani - heritage. Religion might be seen both to ensure legitimate participation (Wenger, 1998) in a Muslim community of practice and to be a source of pride and cohesiveness but could also be seen as being a source of defensiveness which excluded the same people from legitimate participation in the community of practice of the dominant culture. There was some sense of Hundeide's notion (2003) of being a member of a counter-cultural organisation, marked out by expressive style and deep commitment markers, emotional intensity and strict internal discipline as a way of life. 
Greater affluence in the homes of families of Pakistani - heritage, as witnessed by dress and house decoration, seemed to lead to a decline in the presence and significance of external markers of religion in defining ethnic identity. This might suggest that adopting more Western styles of decoration and clothing was a way of 'positioning' themselves (and being positioned) in order to seek entry into some elements of the practices of the middle class Western community, perhaps in order to achieve greater status. How far this affluence might lead to greater status in the dominant society and benefit their children in terms of educational attainment, however, is a different matter. In very few homes of families of Pakistani - heritage did the parents indicate any aspirations or expectations for their children's nursery education. Brooker (2002), Skeggs (2004) and Archer and Francis (2006) argue that economic capital may remain twinned with forms of social and cultural capital that are not seen as valuable and worthwhile by those who hold power, leading to difficulties in being accepted and valued by the dominant culture and to lack of access to dominant educational communities of practice.

In the case of the white families, markers of ethnic identity were difficult to discern, reflecting the invisibility of whiteness (see, for example, Dyer, 1997; Ahmed, 2004). As a white male, middle class researcher, this invisibility came of not being 'other', whilst poverty emerged as a seeming aspect of identity because it was all-too visible and different from my experience. Only in two wealthier white homes, did parents ask any questions about what their children would be doing at nursery, demonstrating knowledge that gave them a shared identity with the staff and which would allow them access to the community of practice (Lave and Wenger, 1991) or cultural capital (Bourdieu and Passeron, 1990) surrounding early childhood education. 


\section{The Nursery Environment and Communities of Practice}

All of the children faced significant differences in the scale and size of the nursery school and its open plan nature in comparison with relatively small, predominantly terraced homes. The types of activities offered (such as painting, drawing, collage, construction, role play, sand and water) were reasonably characteristic of what the wealthier white children may have experienced at home but probably less familiar for the other children. The white homes had relatively few signs of print in relation to what was seen in the poorest Muslim homes because of the significant amounts of text from the Qu'ran. This led to the white children facing a great deal more text at nursery than at home and the children of Pakistani - heritage experiencing a great deal less and what there was did not reflect the Arabic and Urdu found in their homes.

Consistent with the claims of Barth $(1966,1989,2001)$ ethnic identity seemed to be most marked when there was least understanding of the conventions, practices and language and therefore the strongest sense of a boundary. The children who were most hesitant at home and spoke least English, predictably were the ones who were upset when they arrived at nursery. Whilst they did seek contact with the staff, they were often reluctant to play with any of the equipment or materials. It was as though they simply did not know how to engage with the environment in which they found themselves. Many of the nursery school's communities of practice depended on language but significant ones, such as story sessions, were often conducted with no bilingual support. This meant that the majority of the children were unable to access the intended offer of legitimate peripheral participation and so the practices of the nursery served to marginalise them. 
In terms of friendship groupings, it seemed that gender, ethnicity and language formed particular communities of practice, with the children playing largely in same sex, same race groupings.

The white children were more likely to interact with each other than those of Pakistani-heritage and girls of Pakistani-heritage were more likely to interact than boys of Pakistani-heritage. When the lack of ethnic mix in activities was discussed with the staff, this was not something about which they were aware but they appeared to see it as natural and did not seek to increase interaction between the groups.

Eid Preparations: Language, Artefacts and other Boundary Markers of Ethnic and Religious Identity

Story times where Eid was discussed pointed to the ways in which ethnic and religious identities were most marked in relation to an event or boundary that marked out difference. In one story time, where no bilingual support was available, the children showed very little interest in a book about preparing for Eid and were unresponsive but when the practitioner introduced a box of mendhi and clothes to be worn at Eid, the children became very excited and started to clap and laugh and talk to each other. The children were then taken to look at an Eid display, where they got very excited and ran up and down the corridor. At this point, the head teacher appeared and was annoyed, illustrating the ways in which Foucault (2002) argues that schools operate as instruments of surveillance, in this case curtailing a rare nursery experience for which the children had cultural capital. It seemed that many of the practices surrounding Eid were embodied in languages that the staff and children did not share sufficiently but which could be accessed more effectively through the use of 'cultural tools' (Vygotsky, 1978) to shape learning 
and identity. This may explain why the visual, the sensory and the practical appeared to provide ways in which staff and children could participate in and share a little of the practices surrounding Eid celebrations.

Evidence from the study suggests both fixity and fluidity in relation to skin colour, religion and cultural celebrations as elements of ethnic identity. Whilst making his Eid card, a boy of white indigenous-heritage said he would not be celebrating Eid at his house 'because we're not dark are we?' He said, however, that he would like to celebrate Eid because he could get a Spiderman suit for his new clothes. He appeared to associate religious events with skin colour, suggesting a construction of ethnic identity and religion based on colour difference. During story time, a girl of Pakistani-heritage also appeared to see skin colour as a religious and cultural marker in saying that mendhi should not be worn by a 'white woman'. Fluidity in relation to children's experiences of ethnic identity was suggested on another occasion, where the practitioner asked a boy's mother if he had got a new salwar kameez for Eid and she replied 'new clothes, yes'. She was then asked 'are they blue, he says they are blue' and was told 'yes - spiderman clothes'.

\section{Christmas Preparations: Power, Religion, Constructions of Childhood and Diaspora in Experiences of Ethnic Identity}

On returning to the nursery school in December, two elements of the Christmas celebrations were particularly thought - provoking. The first concerned the Christmas cards that the children had made, which included self - portraits using handprints to form the faces of reindeer. Despite the vast majority of the children being of Pakistani - heritage, universally the faces were pink. 
An obvious interpretation would be that the staff had paid no heed to most of the children having brown skin, thereby marginalising them in the process. In discussion with the staff, however, they suggested that the faces were not intended to be pink and simply reflected what had happened when the brown paint had been placed on to blue card. At the very least, however, the pink hand prints raise some questions about the thought that was given to the results.

The second striking feature of the Christmas activities was the performance of a nativity play by a majority of children of Pakistani-heritage. The concert rehearsals pointed again to the significance of language in marking boundaries. Some of the children joined in with the songs but the majority did not. A significant minority did not appear to understand what was happening and responded by shouting and clapping and were then told off. The children who understood least well what was happening in relation to the Christmas celebrations were those with least English. They were also those from the most traditional homes with the strongest signs of non-Western decoration and furniture and the strongest evidence of Islam. Whilst the children were being offered legitimate peripheral participation in the religious, cultural and ethnic practices of the nursery, lack of appreciation of what was not shared in terms of experience and understanding led to marginalisation.

Fixity, anguish and fluidity in relation to conceptualisations of ethnic identity were apparent in discussions with the staff. The head teacher explained that the staff had been discussing the meaning of Christmas in a nursery attended by a majority of Muslim children. She said that the dilemma was really that most of the staff were practising Christians who attended church regularly and felt that their beliefs were compromised if they did not provide (colonize?) the 
children with opportunities to understand and celebrate the meaning of Christmas. In discussion with the rest of the staff, two of the three teachers questioned the relevance of Christmas celebrations whilst the nursery nurses felt that the time and festivities were appropriate and helped develop the children's confidence. Two of the bilingual assistants said that Muslim parents were quite happy for Christmas to be celebrated because they had come to understand the significance that Christmas has in schools. One also said that although her family are devout Muslims, her niece and nephew had a Christmas tree and received Christmas presents each year. In this sense, Christmas was 'performed' in growing numbers of Muslim homes as a cultural but non-religious festival. Perhaps the concerns of the teachers but not of the bilingual assistants point to the ways in which suggesting resistance is easier for those with more power, whilst those with less power learn to perform what they perceive the dominant culture expects and come to see this as part of who they are. It could also be a question of using new-found social and economic capital in order to renegotiate social and cultural identity.

\section{Contemplations on ethnicity, diaspora and research}

It is very difficult to draw more than very tentative conclusions about how the children viewed their own ethnic identity and that of others. Explicit awareness of ethnic identity appeared only rarely and it seemed to be about recognition of boundaries and differences in relation to skin colour, language and personal and religious celebrations and practices. An awareness of kinship and ethnic identity may be seen to be performed in the way in which race appeared to underpin the children's friendship groups but these also operated in articulation with gender, which often seemed to be a more significant aspect in shaping friendships. Ethnic identity also appeared as a silence and a lack of participation in relation to experiences that were not well understood or not 
valued, much in the way that Foucault (1998) suggests. There is a strong sense in which children's ethnic identity is constructed in conjunction with other identities such as gender. The differences in the ways in which this happens, however, appear to reflect factors such as socioeconomic circumstances, education and religion.

What seems to emerge from the research is a sense of complexity, paradox and shifting performances. The children's experiences and practices in relation to ethnic identity demonstrate some elements of 'fixing', often manifested as marginalisation. This was often the result of inability, unwillingness, lack of opportunity or the inappropriateness of 'acting what the dominant culture expects'. There were also signs of considerable fluidity, however, as children moved in and out of overlapping and some times competing communities of practice in relation to ethnic identity, language, class, religion and culture. The research points to the way in which children can be encouraged as participants or marginalised as outsiders and if children from minority groups are not to experience early education as 'other', it seems important that practitioners, parents and children develop genuine dialogue that enables them to work together to create an environment in which all children, parents and staff feel valued, respected and reflected in the provision that is made. It may be that this is challenging and uncomfortable, involving, as it does, the questioning of old certainties and entry into 'diaspora spaces' in order to negotiate new practices in early childhood settings that reflect the coming together of different and shifting ethnic, cultural, class, religious and educational concerns. In so doing, however, it is hoped, as Lather notes (2001, p.481), that it will 'make room for something else to come about'. 


\section{References}

Ahmed, S. (2004). Declarations of Whiteness: The Non-Performativity of Anti-racism. Borderlands ejournal, 3 (2), $69-84$.

Archer, L. \& Francis, B. (2006) Challenging Classes? Exploring the Role of Social Class within the Identities and Achievement of British Chinese Pupils, Sociology, 40 (1), 29 - 49

Aubrey, C., David, T., Godfrey, R. \& Thompson, L. (2000): Early Childhood Educational Research: Issues in Methodology and Ethics (London, Routledge Falmer)

Barth, F. (1966) Models of social organisation, Occasional Paper no. 23, London, Royal Anthropological Institute

Barth, F. (1989) The analysis of culture in complex societies, Ethnos, 54 (3 - 4), 120 - 42

Barth, F. (2000) Boundaries and connections in: A. P. Cohen, (Ed): Signifying Identities (London, Routledge)

Bhabha, H. (1994): The Location of Culture (London, Routledge)

Bourdieu, P. \& Passeron, J-C. (1990) Reproduction in education, society and culture (London, Sage)

Brah, A. (1996) Cartographies of diaspora: contesting identities (London, Routledge)

Bronfenbrenner, U. (1979) The ecology of human development: experiments by nature and design (Cambridge, Mass., Harvard University Press)

Brooker, L. (2002) Starting school: young children learning cultures (Buckingham, OUP)

Butler, J. (1999) Gender trouble: feminism and the subversion of identity, $2^{\text {nd }}$ edition (London, Routledge)

Connolly, P. (1998) Racism, gender identities and young children (London, Routledge)

Corsaro, W. \& Molinari, L. (2000): Entering and Observing in Children's Worlds: A Reflection on a Longitudinal Ethnography of Early Education in Italy in P. Christensen \& A. James:

Research with Children: Perspectives and Practices (London, Falmer Press) 
Deegan, M.J. (2001) The Chicago School of Ethnography, in: P. Atkinson, C. Coffey, S.

Delamont, J. Lofland \& L. Lofland (Eds) Handbook of ethnography (London, Sage)

Dyer, R. (1997) White (London, Routledge)

Emerson, R., Fretz, R. \& Shaw, L. (2001): 'Participant Observation and Fieldnotes', in: P. Atkinson, C. Coffey, S. Delamont, J. Lofland \& L. Lofland (Eds) Handbook of ethnography (London, Sage)

Foucault, M. (1998) The will to knowledge: the history of sexuality 1(London, Penguin)

Foucault, M. (2002) Power: essential works volume 3 (London, Penguin)

Freud, S. (1991) The essentials of psychoanalysis (London, Penguin)

Giddens, A. (1991) Modernity and self identity: self and society in the late modern age (Cambridge, Polity Press)

Goodley, D., Lawthom, R., Clough, P. \& Moore, M. (2004) Researching life stories: method, theory and analyses in a biographic age (London, RoutledgeFalmer)

Gordon, T, Holland, J. \& Lahelma, E. (2001): 'Ethnographic Research in Educational Settings' , in: P. Atkinson, C. Coffey, S. Delamont, J. Lofland \& L. Lofland (Eds) Handbook of ethnography (London, Sage)

Hall, S. (2003): 'New Ethnicities' in L. Alcoff \& E. Mendieta (eds.): Identities: Race, Class, Gender, and Nationality (Oxford, Blackwell)

Hammersley, M. \& Atkinson, P. (1995) Ethnography, $2^{\text {nd }}$ edition (London, Routledge)

Hundeide, K. (2003) Becoming a committed insider, Culture and Psychology, 9 (2), 107 - 127

James, A. (1999): 'Researching Children's Social Competence' in: M. Woodhead, D. Faulkner, \& K. Littlelton (eds): Making Sense of Social Development (London, Routledge)

Lacan, J. (1989) Ecrits: a selection (London, Routledge)

Lather, P. (2001): Postmodernism, Post-structuralism and Post(Critical) Ethnography: of Ruins, Aporias and Angels in: P. Atkinson, C. Coffey, S. Delamont, J. Lofland \& L. Lofland (Eds) Handbook of ethnography (London, Sage) 
Lave, J. \& Wenger, E. (1991) Situated learning: legitimate peripheral participation (Cambridge, Cambridge University Press)

Maclure, M. (2003) Discourse in educational and social research (Maidenhead, OUP)

Nilsen, R.D. (2005) Searching for analytical concepts in the research process: learning from children, Social Research Methodology, 8 (2), 117 - 135

Phinney, J.S. (1990) Ethnic identity in adolescents and adults: review of research, Psychological Bulletin, 108 (3), 499-514

Piaget, J. (1954) The child's construction of reality (London, Routledge and Kegan Paul)

Plummer, K. (2001) The call of life stories in ethnographic research in: P. Atkinson, C. Coffey, S. Delamont, J. Lofland \& L. Lofland (Eds) Handbook of ethnography (London, Sage)

Reay, D. (2005) Beyond Consciousness? The Psychic Location of Social Class, Sociology, 39 (5), $911-928$

Rhedding-Jones, J. (2002) An undoing of documents and other texts: towards a critical multiculturalism in early childhood education, Contemporary Issues in Early Childhood, 3 (1), $90-116$

Sayer, A. (2005) The Moral Significance of Class, (Cambridge, Cambridge University Press)

Skeggs, B. (2004) Class, Self, Culture (London, Routledge)

Sondergaard, D.M. (2002) Theorizing subjectivity: contesting the monopoly of psychoanalysis, Feminism \& Psychology, 12 (4), 445-454

Vincent, c. \& Ball, S.J. (2006) Childcare, Choice and Class Practices: Middle-class parents and their children (Abingdon, Routledge)

Vygotsky, L.S. (1978) Mind in society (London, Harvard University Press) 
Wenger, E. (1998) Communities of practice: learning, meaning and identity (Cambridge, Cambridge University Press)

6996 words including abstract and references 